\title{
Submandibular Gland
}

National Cancer Institute

\section{Source}

National Cancer Institute. Submandibular Gland. NCI Thesaurus. Code C12233.

One of a pair of major salivary glands located below the floor of the mouth. 